\title{
A DECADE OF ANTARCTIC SCIENCE SUPPORT THROUGH AMPS
}

by Jordan G. Powers, Kevin W. Manning, David H. Bromwich, John J. Cassano, and Arthur M. Cayette

AMPS, a real-time mesoscale modeling system, has provided a decade of service for

scientific and logistical needs and has helped advance polar numerical weather prediction

as well as understanding of Antarctica.

W ith 2011 marking the 100th anniversary of Roald Amundsen's being the first to reach the South Pole, the Antarctic endeavor has come a long way. The capabilities to support it have as well. In the critical area of weather forecasting, the Antarctic Mesoscale Prediction System (AMPS) has exemplified this progress for the past decade. AMPS is a real-time implementation of the Weather Research and Forecasting model (WRF; Skamarock et al. 2008) to support the U.S. Antarctic Program (USAP). Because the need for accurate weather forecasting in Antarctica has been acute since the earliest explorations, AMPS has been a vital effort.

AMPS began in 2000, when the National Science Foundation's (NSF's) Office of Polar Programs (OPP) sought to improve the weather forecasting support for the USAP. The concern at the time was the numerical weather prediction (NWP) guidance available to the USAP forecasters, who were relying on an assortment of models (mostly global) that were tailored neither to their needs nor to their singular area of responsibility. The response was the Antarctic Mesoscale Prediction System, which was to be a real-time modeling capability to support the meteorologists at the main American base, McMurdo Station (Fig. 1).

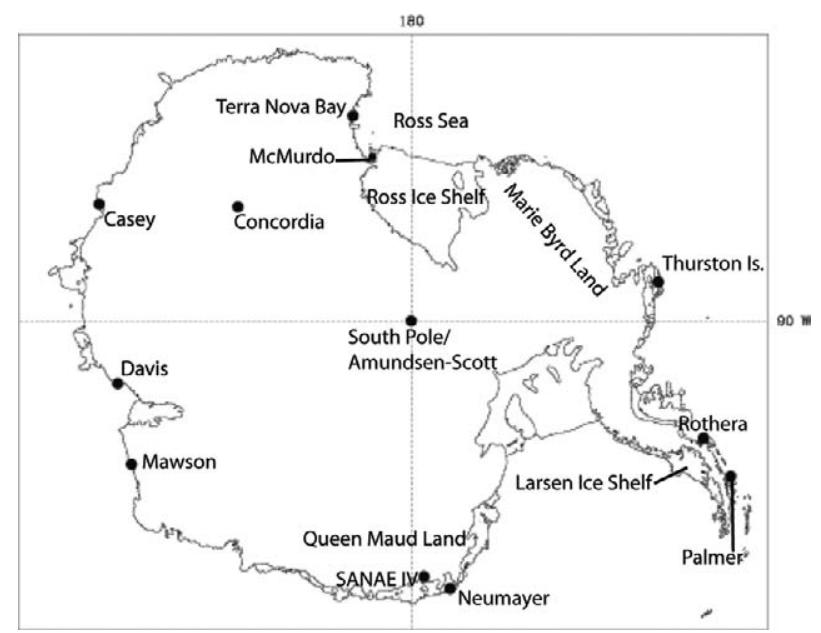

FIG. I. Antarctica, with referenced locations and regions shown.

It became evident early in the effort that the system could be of value to Antarctic activities beyond those tied to the McMurdo forecasters. In particular, AMPS could be of significant interest to the international Antarctic community, for which science drives operations in a unique environment of cooperation. ${ }^{1}$ Indeed, after a decade, AMPS's service

${ }^{1}$ The Antarctic Treaty is an agreement regulating the relations of the countries operating in the Antarctic. Currently signed by 48 nations, it directs that Antarctica shall be used for peaceful purposes only, that freedom of scientific investigation in Antarctica and cooperation toward that end shall continue, and that scientific observations and results from Antarctica shall be exchanged and made freely available. 
has extended to far beyond the original American target group.

AMPS is currently a collaboration of the National Center for Atmospheric Research (NCAR) and the Polar Meteorology Group of the Byrd Polar Research Center at The Ohio State University (OSU). This paper summarizes the system and service that is AMPS and reports on the returns on NSF's investments over its first decade. AMPS is positioned to support a range of science in Antarctica, and researchers with either field activities or data needs may consider how it may be of help.

BACKGROUND. Motivations. Limited-area atmospheric models have been applied to the Antarctic since the late 1980s (see, e.g., Parish and Waight 1987; Parish and Bromwich 1991; Gallée 1995; Engels and Heinemann 1996). Prior to AMPS, however, real-time NWP over Antarctica was generally the province of global models run by operational centers [e.g., National Centers for Environmental Prediction (NCEP), the U.S. Navy, and European Centre for Medium-Range Weather Forecasts (ECMWF)]. ${ }^{2}$ In October 1999, a medical evacuation of Amundsen-Scott (South Pole) Station's physician, Dr. Jerri Nielsen (Nielsen 2001), brought attention to the suboptimal forecasting support tools then available. This preliminary impetus for the AMPS concept was followed in May 2000 by the Antarctic Weather Forecasting Workshop hosted by OSU's Byrd Polar Research Center. In reviewing the state of weather forecasting over Antarctica, the workshop recognized that guidance from NWP models was a key input for the meteorologists at McMurdo Station, whose

AfFiliations: Powers ANd Manning-National Center for Atmospheric Research, Boulder, Colorado; BROMWICH-Polar Meteorology Group, Byrd Polar Research Center, The Ohio State University, Columbus, Ohio; CASSANO-Cooperative Institute for Research in Environmental Sciences, and Department of Atmospheric and Oceanic Sciences, University of Colorado, Boulder, Colorado; CAYETTE-Space and Naval Warfare Systems Center, North Charleston, South Carolina

CORRESPONDING AUTHOR: Dr. Jordan G. Powers, MMM Division, NCAR Earth System Laboratory, NCAR, P.O. Box 3000, Boulder, CO 80307-3000

E-mail:powers@ucar.edu

The abstract for this article can be found in this issue, following the table of contents.

DOI:10.1175/BAMS-D-II-00186.1

In final form 19 April 2012

(C)2012 American Meteorological Society mission was critical for the USAP. It found, however, that the guidance from the existing global models was lacking due to 1) the inadequate horizontal resolution used to resolve mesoscale features affecting short-term (6-24 h) forecasting and flight operations; 2) the inadequate representation of physical properties uniquely affecting the Antarctic atmosphere [e.g., planetary boundary layer (PBL), surface]; and 3) the poor representation of Antarctic topography and surface features (Bromwich and Cassano 2001). A key conclusion from the workshop was thus the need to improve numerical weather prediction for the Antarctic through a focused mesoscale modeling initiative.

The workshop report recommended to NSF the provision of robust NWP capabilities for, and products tailored to, the needs of the USAP forecasters. It also recommended the improvement of guidance through higher-resolution forecast domains (i.e., grid sizes $\leq 15 \mathrm{~km}$ ). This reflected the fact that in the Ross Island (McMurdo) region elevations run from sea level to $>3000 \mathrm{~m}$, and the complex topography strongly influences local circulations and weather (see, e.g., O'Connor et al. 1994; Seefeldt et al. 2003; Powers 2007). Last, the report recommended a program for improving model parameterizations for the Antarctic and for performing verification. In light of this, AMPS was conceived, with funding from NSF. The AMPS project goals were as follows:

1) provide real-time mesoscale and synoptic model products for Antarctica, tailored to the needs of the forecasters at McMurdo Station;

2) improve and incorporate model physical parameterizations for the Antarctic;

3) perform qualitative and quantitative system verification; and

4) stimulate close collaboration among forecasters, modelers, and researchers by sharing the model output and results with the community through the web, an archive, and workshop interactions.

Since late 2000, AMPS has supported forecasting for the seasonal (October-March) forecasting for missions between Christchurch, New Zealand, and McMurdo Station, and between McMurdo and the South Pole, and for activities year-round at the American bases and field camps. AMPS has served

\footnotetext{
${ }^{2}$ The Antarctic Limited Area Prediction System was an exception, forecasting on the mesoscale in Antarctica and developed by the Australian Bureau of Meteorology, which became operational in 1999 (see Adams 2004)
} 
a variety of scientists and disciplines addressing the high southern latitudes, and, as shown below, over its first decade it has far surpassed the original aims.

The system. At its start AMPS employed the fifthgeneration Pennsylvania State University-National Center for Atmospheric Research Mesoscale Model (MM5; Grell et al. 1995). The MM5 code in AMPS soon gained modifications to better capture highlatitude conditions, for example, more accurate radiative and thermal characteristics of ice sheets. The modifications were originally developed by the Polar Meteorology Group of the Byrd Polar Research Center (Bromwich et al. 2001; Cassano et al. 2001), and the optimized model was referred to as the Polar MM5. Later, the modifications were adapted to WRF (Polar WRF), and both modified models have been assessed in the Arctic and Antarctic (Bromwich et al. 2001; Cassano et al. 2001; Guo et al. 2003; Hines and Bromwich 2008; Powers 2009; Bromwich et al. 2009; Hines et al. 2011; Cassano et al. 2011).

In its initial AMPS configuration, the MM5 was run in a nested-domain setup with grids of 90-, $30-$, and $10-\mathrm{km}$ horizontal spacing. As computing power expanded, grids were added and resolutions increased. A 60-/20-/6.67-/2.22-km grid configuration ran from September 2005 to November 2008. WRF was implemented in March 2006, and MM5 continued to run in parallel with it until June 2008. WRF currently runs twice daily, with 0000 and 1200 UTC initializations. Figure 2 shows the domain configuration, and the horizontal spacings for the six main WRF grids stand at 45, 15, 5, and $1.67 \mathrm{~km}$. The coarser 45 - and $15-\mathrm{km}$ grids run out to 5 days, while the 1.67- (Ross Island) and 5-km grids run for $36 \mathrm{~h}$. All of the grids within the $45-\mathrm{km}$ domain are two-way nested. In the vertical, WRF has 44 terrain-following levels with the highest resolution near the surface, the lowest level at $\sim 13 \mathrm{~m}$ above the surface, and a model top at $10 \mathrm{hPa}$.

In addition to the main forecast grids, AMPS runs one-way ${ }^{3}$ forecast grids providing locally higher resolution over areas with special field activities. These domains have covered regions over the Antarctic Peninsula, the central Transantarctic Mountains, West Antarctica, and the South Atlantic/Indian Oceans.

WRF gets its first-guess field and boundary conditions from output of the NCEP Global Forecast
System (GFS; NOAA Environmental Modeling Center 2003). For data assimilation, the model uses the WRF Data Assimilation System (WRFDA; Barker et al. 2004) with a three-dimensional variational data assimilation (3DVAR) approach. At present the observation types ingested include surface data, upper-air soundings, aircraft observations, geostationary and polar-orbiting satellite atmospheric motion vectors (AMVs), Constellation Observing System for Meteorology, Ionosphere, and Climate (COSMIC), GPS radio occultations, and Advanced Microwave Sounding Unit (AMSU) radiances. The observations assimilated are listed online (www.mmm.ucar.edu/rt /amps/information/obs.html).

As mentioned above, WRF in AMPS employs polar modifications to better represent high-latitude conditions. ${ }^{4}$ These include, for example, a fractional sea ice representation and adjustments to the thermal and radiative properties of ice and snow surfaces. The WRF modifications were extended from those made for the MM5 (Bromwich et al. 2001; Cassano et al. 2001). Over the years the polar modifications have been found to improve AMPS forecast performance (Powers 2009), as well as other high-latitude WRF applications (see, e.g., Hines and Bromwich 2008; Bromwich et al. 2009; Cassano et al. 2011). Polar code was merged into the official released WRF with version 3.1 in 2009, and developments are added to the regular releases. This evolution is an example of the effort's model development benefitting the broader scientific community.

Products. AMPS forecast products range from traditional charts (e.g., surface and upper air) to animated fields. Popular products are tables of weather parameters and meteograms at stations/camps across the continent (Fig. 3). AMPS also generates plotting windows, displaying subareas of the forecast grids. These most commonly serve foreign requests.

AMPS forecast products are disseminated via the web, e-mail, and the Antarctic Internet Data Distribution (IDD; see below). The primary route is via the AMPS site (www.mmm.ucar.edu/rt/amps). This is open access (no password required), so anyone can obtain the daily forecast information. By contacting AMPS, those with limited bandwidth (e.g., on ships) can receive products via e-mail.

The Antarctic IDD (Lazzara et al. 2006) system also disseminates AMPS output. The Antarctic

\footnotetext{
${ }^{3}$ The one-way nests derive their boundary conditions from the grid one level above.

${ }^{4}$ Details on the polar modifications to WRF can be found in Hines and Bromwich (2008), Bromwich et al. (2009), and Hines et al. (2011).
} 


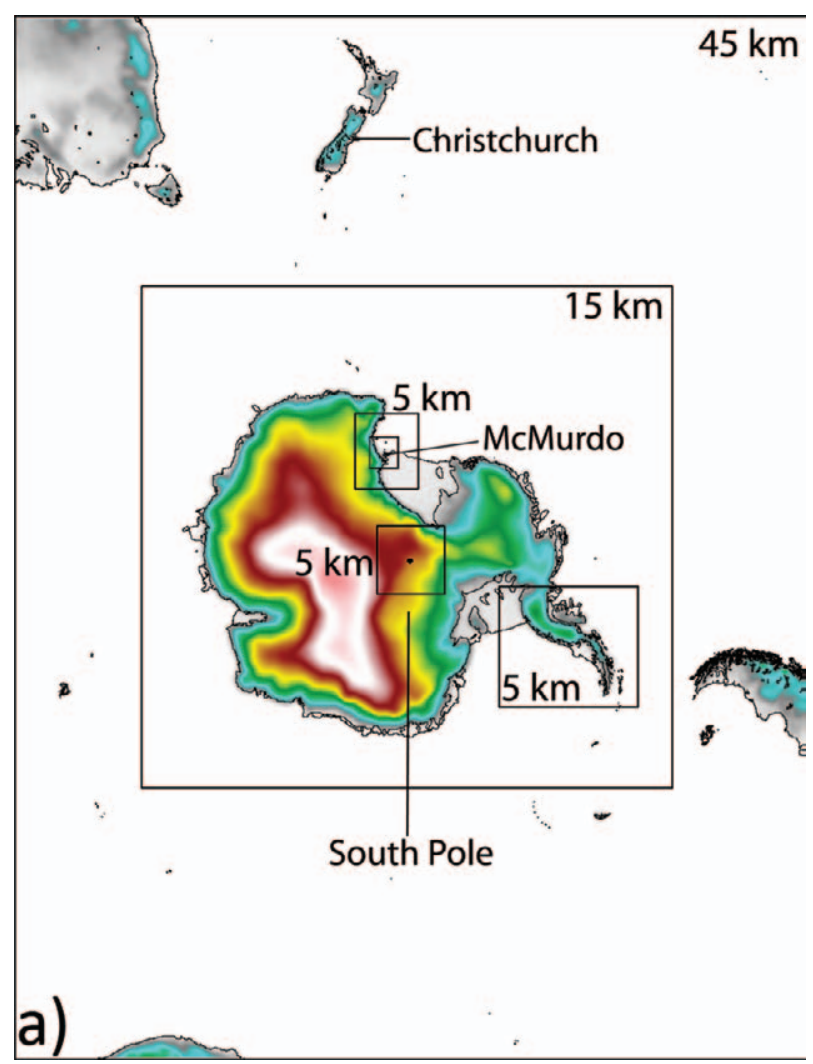

FIG. 2. WRF model grids in AMPS: (a) 45- (Southern Ocean) and $15-\mathrm{km}$ (Antarctic continent) grids, (b) I5and 5-km (western Ross Sea, South Pole, and Antarctic Peninsula) grids, and (c) 5- (western Ross Sea) and I.67-km (Ross Island area) grids.

IDD effort is a collaboration to broadcast Antarctic weather information-both observations and AMPS output-using Unidata's Local Data Manager (LDM) data-sharing software (see www.unidata.ucar.edu /software/ldm). ${ }^{5}$ AMPS injects forecast output in gridded binary (GRIB) format as well as graphical images into the Antarctic IDD. The distributed AMPS information includes model winds, temperatures, water vapor, hydrometeors, relative humidity, precipitation, and sea level pressure (SLP) at the surface and multiple vertical levels.

One unique product from AMPS uses selforganizing maps (SOMs; see Hewitson and Crane 2002; Cassano et al. 2007) to evaluate the likelihood that a predicted synoptic weather pattern will verify. This can give forecasters an idea of the probability of the particular scenario occurring. As an example, in Fig. 4 the panels (referred to as "nodes") are 20 SLP patterns (mean removed) that have been objectively

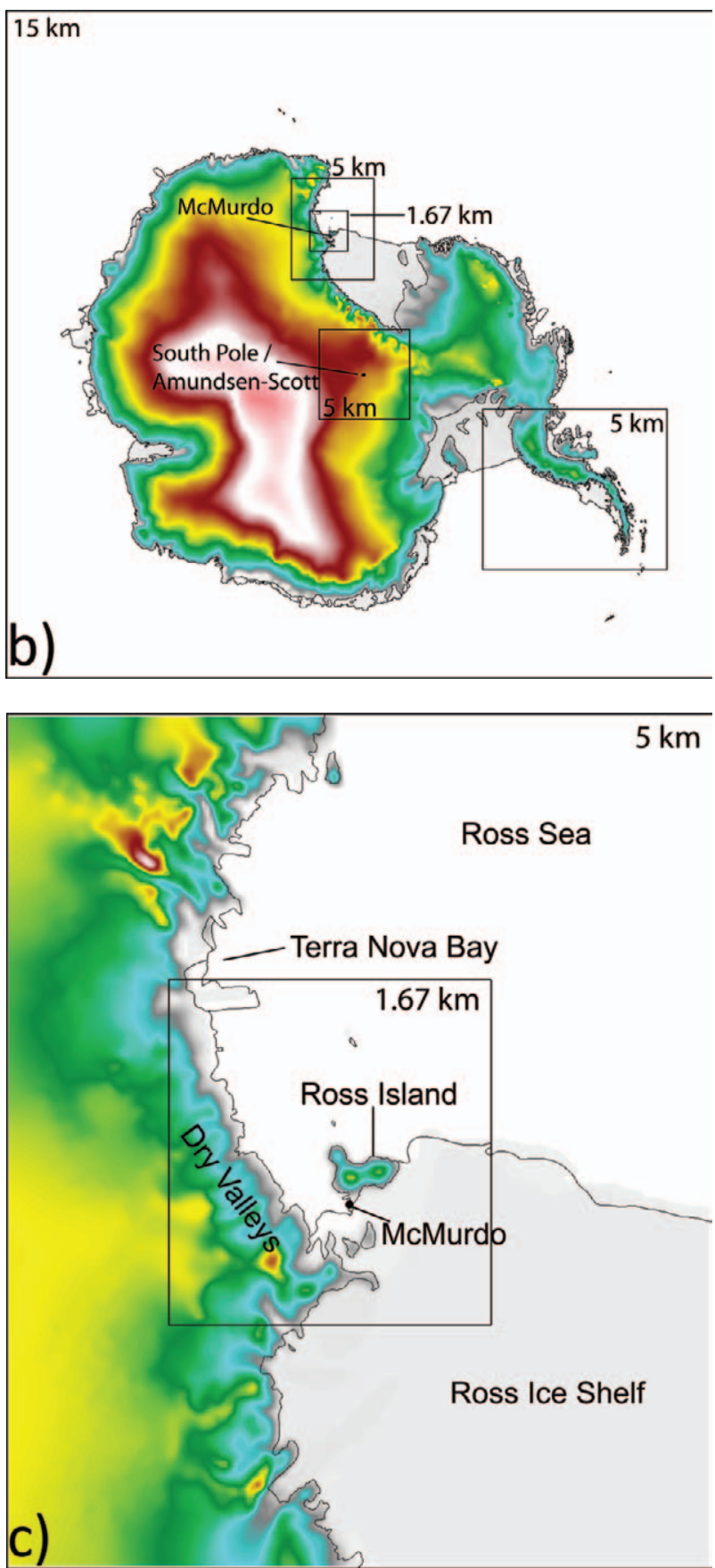

identified using a SOM algorithm. The node that most closely matches the forecast SLP pattern predicted in the given forecast period (here $24-33 \mathrm{~h}$ ) is highlighted. The percentages shown give the probability of each forecast pattern being verified, based on statistics from a period of previous forecasts. The value of $67.9 \%$ for the highlighted node means that this forecast SLP pattern is verified $67.9 \%$ of

\footnotetext{
${ }^{5}$ The LDM utility is a system for event-driven data distribution, consisting of software for processing and sending data products using network client/server programs and protocols.
} 


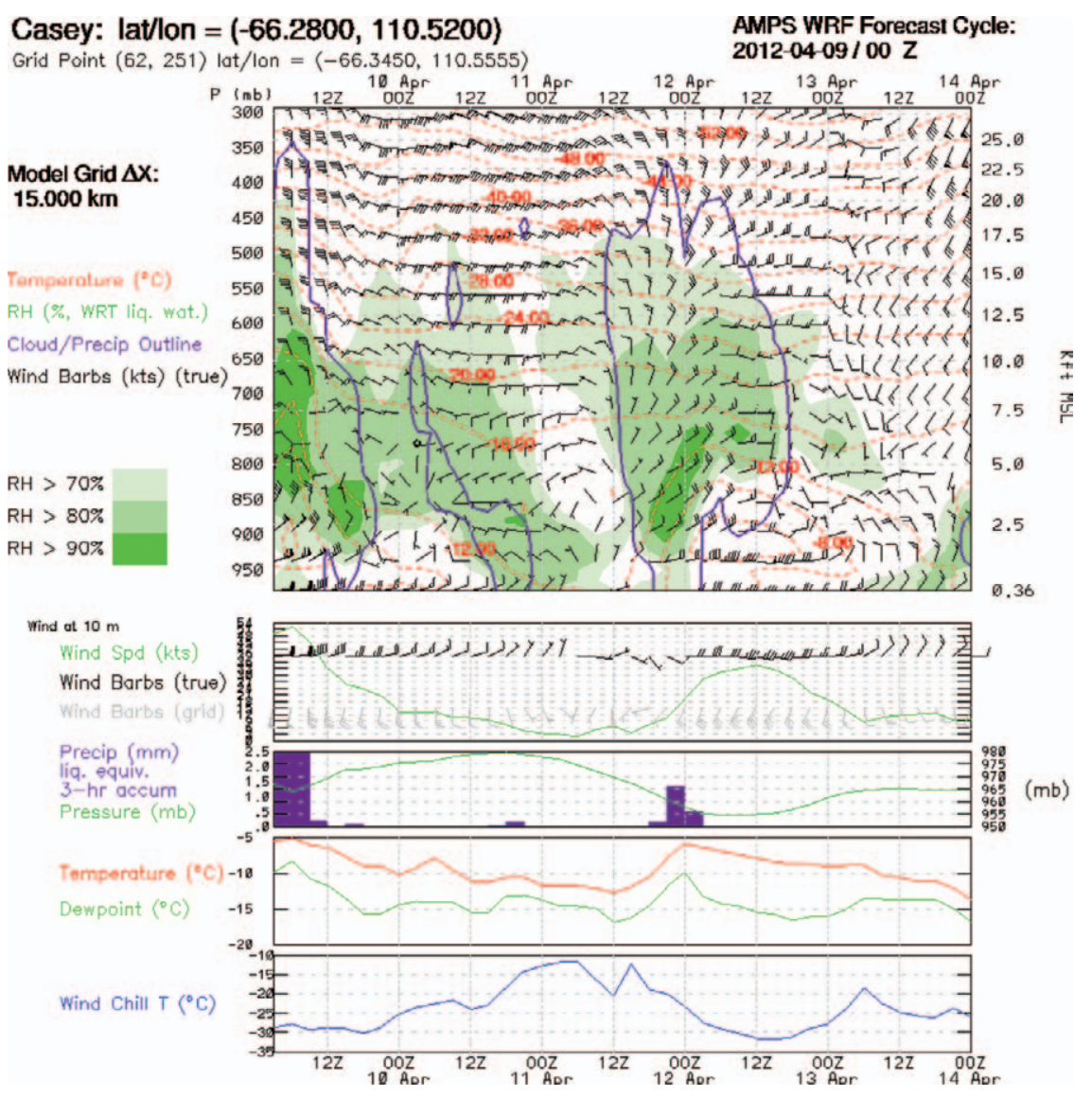

Fig. 3 (Left). AMPS meteogram, Casey Station (Australia). Forecast period: 0000 UTC 9 Apr-0000 UTC 14 Apr 2012. (top) Timeheight cross section of winds (barbs), relative humidity, temperature, and outline of cloud/precipitation, and (bottom) time series: (from top to bottom) wind speed/ direction, 3-hourly precipitation and pressure, temperature and dewpoint, and wind chill.

Fig. 4 (Below). AMPS SOM product. SLP SOM for 24-33-h forecast period shown for 0000 UTC 15 Jul $201 \mathrm{I}$ initialization. Forecast pattern framed in boldface. Field plotted is SLP $(\mathrm{hPa})$, with mean removed; positive (red) and negative (blue) anomalies are shown. Probability (\%) of the forecast pattern appearing is shown.

the time. Here, the likelihood of the flanking nodes, which are variations of the highlighted pattern, are $16.7 \%$ and $9.0 \%$, respectively. These types of plots indicate the probability of occurrence of not only the model-predicted pattern but also of others.

Forecast evaluation. Performance assessment of AMPS occurs on an ongoing basis through varying means. For example, multiyear AMPS forecast evaluations have been conducted (Bromwich et al. 2005). In system development, forecast verifications for both warm- and cold-season periods are done prior to changes in model versions or configurations (e.g., implementation of a new

Forecast hours 24-33; Node $(3,0)$ Predicted

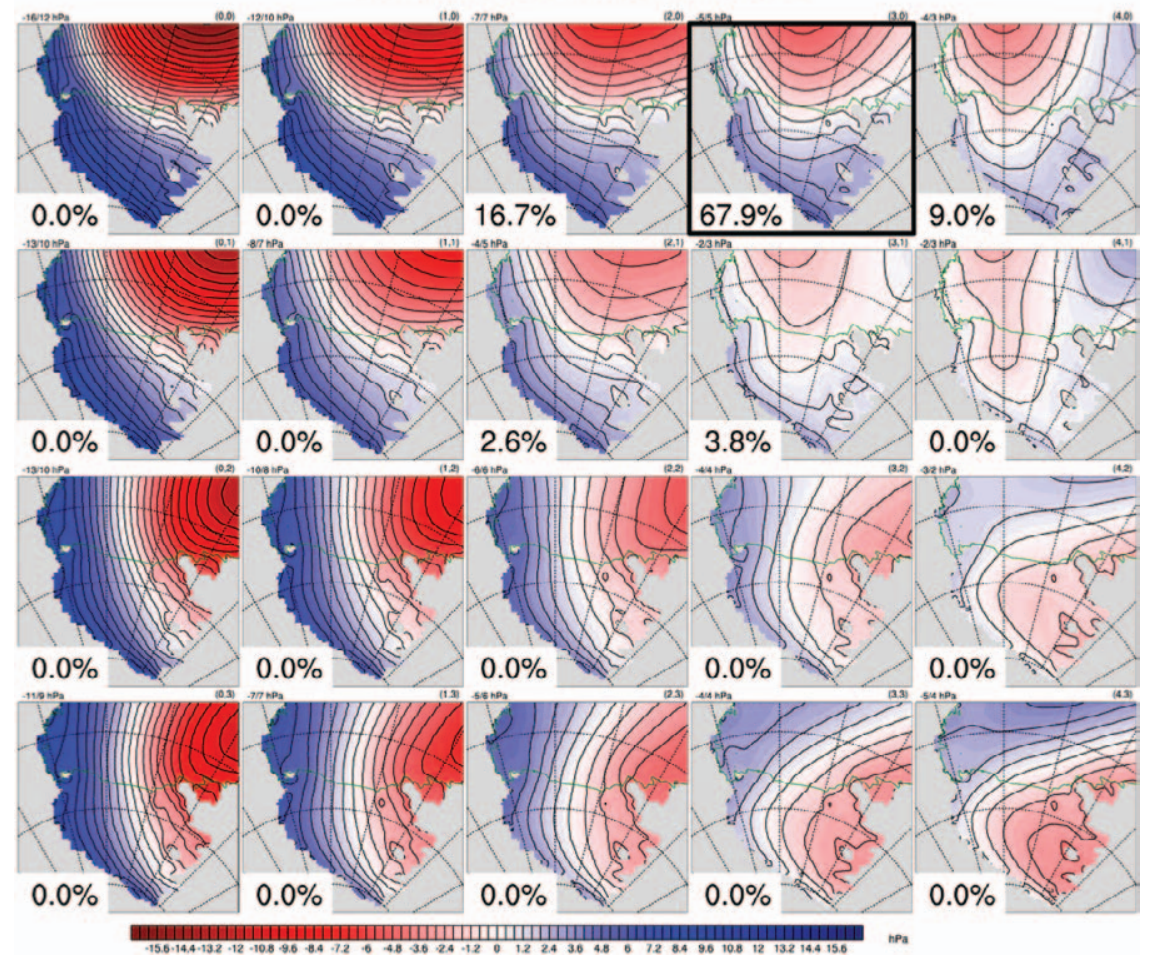

physics package). The models used in AMPS have been evaluated over Antarctica outside of the specific 
AMPS configuration, for example, such as the analysis of a year of simulations from the polar-modified MM5 by Guo et al. (2003).

AMPS review also occurs through the regular scrutiny of model runs by the Space and Naval Warfare Systems Center (SPAWAR), which the USAP engages to provide the weather forecasting. Beyond this, international users also contribute to AMPS verification (e.g., Adams 2010), analyzing AMPS performance in sectors and locations outside of the USAP's areas of operation (e.g., East Antarctica, Queen Maud Land).

Case study verification is also done and has addressed noteworthy forecast events or scenarios (e.g., Bromwich et al. 2003; Powers 2007). Powers (2007), for example, showed that AMPS can capture high-impact weather events, while Nigro et al. (2011a) evaluated the ability of AMPS to forecast cyclones in the western Ross Sea by comparing modeled systems with satellite-observed systems. Last, SOMs have also been applied for AMPS verification, an approach that can reveal errors that vary with synoptic pattern (Nigro et al. 2011b).

APPLICATIONS. USAP forecasters. SPAWAR issues all weather forecasts for the USAP and uses AMPS as its principal numerical guidance. SPAWAR's forecasting for the USAP is dominated by the needs of air operations, both inter- and intracontinental (i.e., Christchurch-McMurdo, McMurdo-South Pole, McMurdo-field camps). The U.S. Air Force's 304th Expeditionary Airlift Squadron and the New York Air National Guard's (NYANG) 109th Airlift Wing command the heavy lift air transport for the USAP, and Fig. 5 shows one of the primary aircraft involved, an Air Force C-17, at McMurdo. The

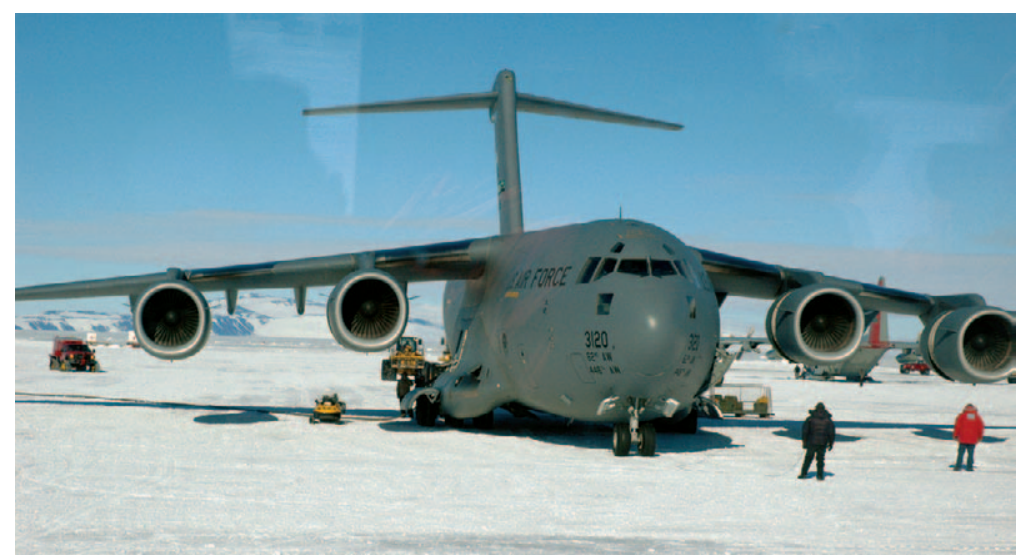

FIG. 5. U.S. Air Force C-I7 at McMurdo Station. AMPS supplies model forecast guidance to SPAWAR forecasters for its weather forecasting for the operations of these heavy lift aircraft and others.
SPAWAR forecasting also supports the air operations of the smaller aircraft (namely, Twin Otter) of Kenn Borek Air, Ltd., and the helicopters of Petroleum Helicopters, Inc., that fill that transport niche for the USAP. SPAWAR also does marine area forecasting. This is for the NSF Research Vessels (R/Vs) Nathaniel B. Palmer and Laurence M. Gould when they operate south of $60^{\circ} \mathrm{S}$, as well as for the forecasting for the annual icebreaker and supply ship convoy to McMurdo in the austral summer. The SPAWAR forecasters provide feedback for system improvements and new products, and this has contributed to the development of a reliable NWP system tailored for them, which is one of the original motivations of AMPS.

AMPS has reduced the number of costly flight aborts on the intercontinental ChristchurchMcMurdo route. These run about $\$ 150,000$ per occurrence for each C-17 and up to $\$ 100,000$ per occurrence for each LC-/C-130. For the period primarily before AMPS (August 1997-February 2001), an average of 7.5 planes per season (intercontinental) were turned back. For the period of August 2001-08, this average dropped to 3.6 planes per season. Using an average of $\$ 125,000$ per turnaround, such a cost reduction would translate to about $\$ 487,000$ per season. This partial estimate, however, considers only the category of aircraft operating costs. Other costs saved reflect lost/delayed missions and their consequential logistical costs and science losses, additional personnel time, and opportunity costs. Above all, though, are the reduced risk to lives and the enhanced safety of flight and ground operations.

Scientific field campaigns. AMPS has supported science over the decade through assistance to field campaigns. AMPS's role is typically in providing model grids, plotting windows, or specialized products over the study areas. Table 1 lists the field campaigns that AMPS has supported, and these range from meteorological, to oceanographic, to geological, to glaciological. In addition, National Aeronautics and Space Administration's (NASA's) Columbia Scientific Balloon Facility (CSBF) uses AMPS in launches of its high-altitude, long-duration research balloons at McMurdo.

AMPS provides guidance for the cruises through the Ross Sea of both of NSF's research vessels, the Palmer 
TABLE I. Field campaigns and activities involving AMPS forecast support.

\begin{tabular}{|c|c|c|}
\hline Campaign & Period & Discipline/activity \\
\hline Global Ocean Ecosystem Dynamics (GLOBEC) & $2002+$ & $\begin{array}{l}\text { Ecology; } \\
\text { Marguerite Bay, Antarctica region }\end{array}$ \\
\hline $\begin{array}{l}\text { Dronning Maud Land Nonlinear Equation of State } \\
\text { System Study (MaudNESS) }\end{array}$ & 2005 & $\begin{array}{l}\text { Oceanography; } \\
\text { Weddell Sea cruise }\end{array}$ \\
\hline West Antarctic Ice Sheet (WAIS) Divide Ice Core & $2005+$ & $\begin{array}{l}\text { Glaciology; } \\
\text { Forecast products for planning and site location }\end{array}$ \\
\hline Pine Island Bay Survey & 2007 & $\begin{array}{l}\text { Glaciology; } \\
\text { Survey of Pine Island Bay Glacier region; Research flights } \\
\text { from South America }\end{array}$ \\
\hline Columbia Scientific Balloon Facility (CSBF) & $2007+$ & $\begin{array}{l}\text { Atmospheric sciences; Astronomy launches of high-altitude, } \\
\text { long-duration balloons from McMurdo }\end{array}$ \\
\hline Antarctica's Gamburtsev Province (AGAP) & $2008-10$ & $\begin{array}{l}\text { Geology; } \\
\text { Surveys of Gamburtsev Subglacial Mountains }\end{array}$ \\
\hline Terra Nova Bay Polynya Study & 2009 & $\begin{array}{l}\text { Meteorology; } \\
\text { Study of PBL in Terra Nova Bay region; UAV flight forecasting }\end{array}$ \\
\hline Larsen Ice Shelf System, Antarctica (LARISSA) & $2009-10$ & $\begin{array}{l}\text { Meteorology, glaciology; } \\
\text { Helicopter and field activity forecasting }\end{array}$ \\
\hline IceBridge & $2009-10$ & $\begin{array}{l}\text { Glaciology; } \\
\text { NASA study of Antarctic ice sheets, glaciers, sea ice; } \\
\text { Flight forecasting products }\end{array}$ \\
\hline $\begin{array}{l}\text { Orographic Flow and Climate of the Antarctic } \\
\text { Peninsula (OFCAP) }\end{array}$ & 2011 & $\begin{array}{l}\text { Meteorology, climatology; } \\
\text { Study of flow over the Antarctic Peninsula }\end{array}$ \\
\hline $\begin{array}{l}\text { R/V Nathaniel B. Palmer and } \\
\text { R/V Laurence M. Gould Antarctic cruises }\end{array}$ & $2011-12$ & Ross Sea cruises of NSF's Palmer and Gould \\
\hline Pine Island Glacier Study & $2011-12$ & Field camps at Pine Island Glacier for glacial survey \\
\hline
\end{tabular}

and Gould. For this application, a new, ship-following plot view (window) was developed to keep the forecast charts centered on the moving vessel. Figure 6 gives an example. The Palmer appears in the western Ross Sea, and the low to the southwest of the vessel is an example of the mesoscale cyclones that frequently form near Terra Nova Bay (Bromwich 1991). In January 2012, AMPS products also aided the Italian Antarctic Program and its research ship, the Motor Vessel (M/V) Italica. The Italica rendezvoused with the Palmer for a fuel transfer in the Ross Sea. AMPS weather guidance aided decisions concerning the orientation of the two ships in the sea ice.

In September 2009, the University of Colorado led a field study to investigate the Terra Nova Bay polynya using unmanned aerial vehicles (UAVs) flying out of McMurdo (Cassano et al. 2010). For this, AMPS delivered special products (Fig. 7) for the planning of UAV missions. AMPS forecasts of large upward sensible heat flux, appearing prominently in Fig. 7 (red areas), were used to identify periods when open water and high winds occurred over Terra Nova Bay, yielding strong air-sea coupling, one of the basic study aims of the campaign. The daily, satellite-derived fractional sea ice analyses input to WRF combined with the model's ability to predict the strength of the winds in these areas allowed these features to be resolved.

International use. The countries active in Antarctica share the objective of scientific exploration (per the Antarctic Treaty; see www.ats.aq/index_e.htm), and they team up for logistical operations. In the spirit of Antarctic cooperation, AMPS early on added products to assist foreign, non-USAP groups. The forecast information sought most has been stationspecific data, such as soundings, surface tables, and meteograms. Regional windows are also popular, and AMPS generates these for Queen Maud Land (German forecasting), the Davis/Mawson and Casey Station region (Australian forecasting), and the South Atlantic (South African forecasting).

Nations that AMPS has served include Italy, Australia, United Kingdom, Germany, South Africa, China, Chile, Norway, Russia, and Japan. A consortium of countries using AMPS is the Dronning Maud Land Air Network (DROMLAN). The DROMLAN 


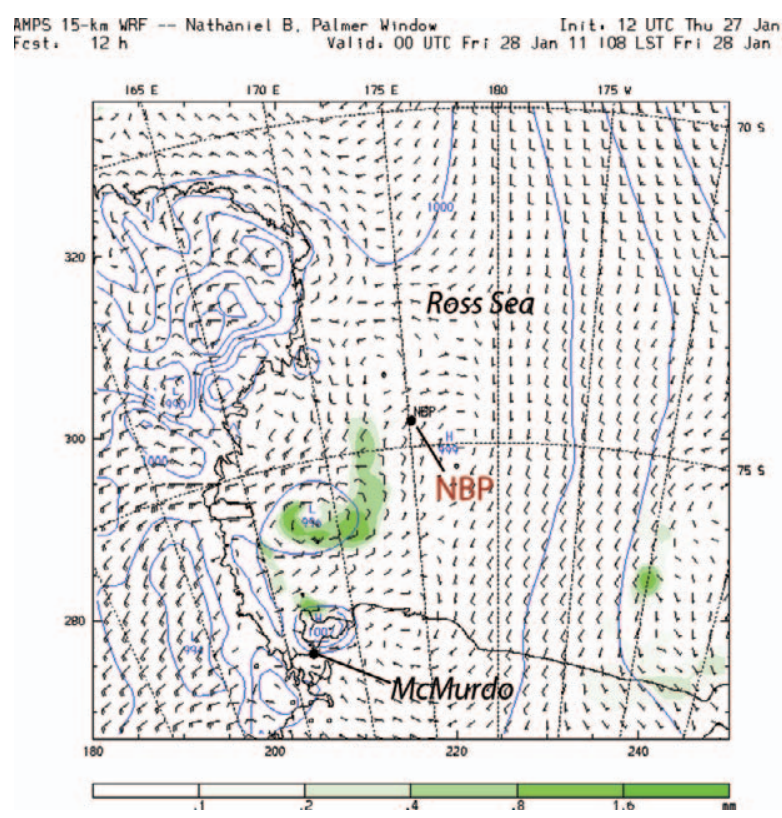

FIG. 6. AMPS plotting window following the $R / V$ Nathaniel B. Palmer during its 201 I Ross Sea cruise. The I2-h AMPS forecast shown, valid at 0000 UTC 28 Feb 20II. Winds (barbs, full barb = $10 \mathrm{kt}$; I kt $\approx 0.5144 \mathrm{~m} \mathrm{~s}^{-1}$ ), SLP sea level pressure (contours, interval $=2 \mathrm{hPa}$ ), and 3-hourly accumulated precipitation (shaded, $\mathrm{mm}$, scale at bottom) are shown. "NBP" marks the location of the Palmer.

nations are Germany, Russia, Belgium, Finland, India, Japan, Netherlands, Norway, South Africa, Sweden, and United Kingdom, and they pool resources for logistical needs (e.g., air transport and forecasting) for the Queen (Dronning) Maud Land sector. The typical application of AMPS is for forecasting at bases, for both ground and air operations. Examples are used by the German forecasters at Neumayer Station (who forecast for DROMLAN operations) or the Australian users at Casey Station (Fig. 1), who are provided specialized products. ${ }^{6}$ Last, AMPS has also assisted foreign research and supply cruises in the form of one-way nests and location-specific products.

Antarctic rescues-Emergency situations. Antarctica's remoteness and seasonal inaccessibility can quickly amplify problems into crises. Throughout the AMPS era, the rescue of personnel has been necessary, and the system has been there to assist in these circumstances; most often these cases are medical, and Table 2 lists the episodes.

AMPS's first emergency support was in the high-profile medevac of the station physician at

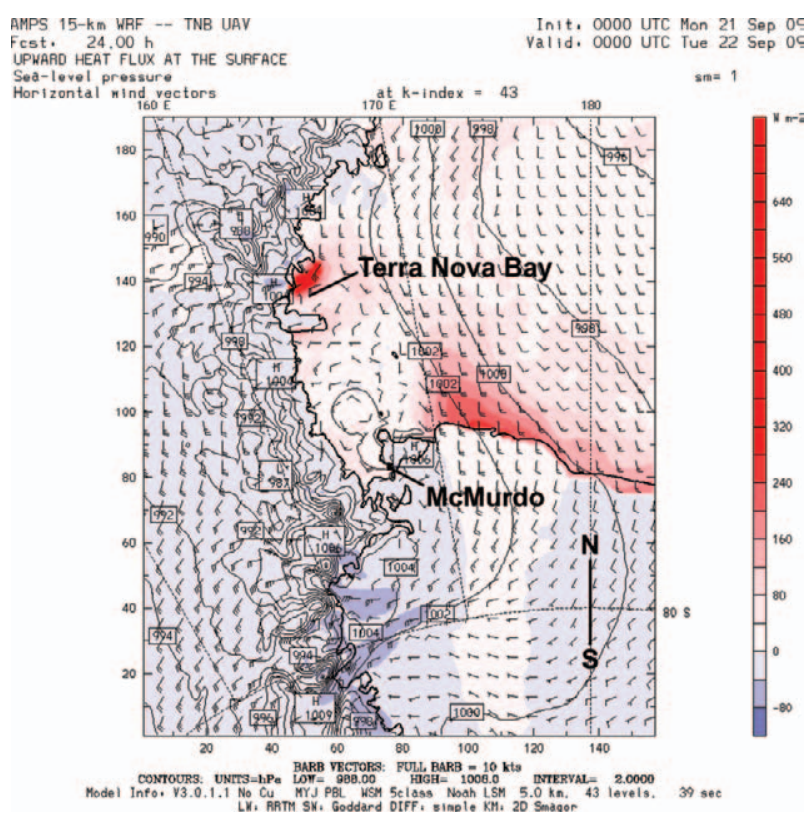

Fig. 7. Forecast plot produced for Terra Nova Bay polynya field campaign. Fields shown are near-surface winds and surface sensible heat fluxes. Wind barbs: full barb $=10 \mathrm{kt}$. Surface sensible heat fluxes $\left(\mathrm{W} \mathrm{m}^{-2}\right.$; shaded) are shown. The enhanced areas of upward sensible heat flux (red) are those of the Terra Nova Bay and Ross Sea polynyas.

Amundsen-Scott base in April 2001. It was long after the season had ended, and the deepening cold at the Pole made the Twin Otter (aircraft) flight to extract the ailing doctor risky. As described in Powers et al. (2003) and Monaghan et al. (2003), AMPS provided one of the real-time models for the mission from Rothera to the Pole (Fig. 1). It accurately predicted a period in which blowing snow at the Pole would cease, contributing to the rescue (Monaghan et al. 2003). Marine emergencies arise, too, and AMPS was successfully used by the South African Weather Service in the June 2002 mission to the German ship Magdalena Oldendorff, which was trapped in sea ice on the Queen Maud Land (Fig. 1) coast (for details, see Powers et al. 2003).

Over the past decade, emergency situations involving AMPS assistance have occurred, on average, every 13 months. Recently, in October 2011, a Raytheon worker who had suffered a stroke at Amundsen-Scott base was evacuated, with the rescue aircraft flying from Rothera (Fig. 1) to the Pole, to McMurdo. AMPS was used by the flight forecasters, contributing to a successful evacuation. Future

\footnotetext{
${ }^{6}$ The forecasters use AMPS in conjunction with other modeling systems available to them, such as those from the ECMWF or the Australian Bureau of Meteorology.
} 
TABLE 2. Rescues and emergency situations for which AMPS has been used in forecasting support. "Medevac" refers to a medical evacuation.

\begin{tabular}{|c|c|c|}
\hline Emergency & Date & Station/Location \\
\hline $\begin{array}{l}\text { Medevac; } \\
\text { Evacuation of station physician from South Pole }\end{array}$ & Apr 200I & Amundsen-Scott \\
\hline $\begin{array}{l}\text { Magdalena Oldendorff rescue; } \\
\text { Rescue of personnel aboard supply ship Magdalaena Oldendorff; } \\
\text { Dispatch of South African rescue ship and Argentinian icebreaker; } \\
\text { AMPS outer grid extended to South Africa }\end{array}$ & Jun-Jul 2002 & Queen Maud Land coast \\
\hline $\begin{array}{l}\text { South Pole medevac; } \\
\text { AMPS Antarctic Peninsula grid added }\end{array}$ & Sep 2003 & Amundsen-Scott \\
\hline Medevac & Apr 2004 & McMurdo \\
\hline Medevac & Oct 2008 & Troll (Norway) \\
\hline $\begin{array}{l}\text { Medevac; } \\
\text { Evacuation of personnel injured in ATV accident; } \\
\text { NYANG LC-I30 aircraft dispatched }\end{array}$ & Nov 2008 & Casey (Australia) \\
\hline $\begin{array}{l}\text { Medevac; } \\
\text { New Zealand P-3 aircraft dispatched }\end{array}$ & Sep 2010 & McMurdo \\
\hline $\begin{array}{l}\text { Medevac; } \\
\text { Rescue aircraft flown from McMurdo }\end{array}$ & Jan 2011 & Concordia (France/Italy) \\
\hline $\begin{array}{l}\text { Medevac; } \\
\text { Evacuation of man from McMurdo; } \\
\text { U.S. Air Force C-I7 dispatched }\end{array}$ & Jun 2011 & McMurdo \\
\hline $\begin{array}{l}\text { Medevac; } \\
\text { Evacuation of woman from South Pole; } \\
\text { Kenn Borek Air DC-3 Basler dispatched }\end{array}$ & Oct 2011 & Amundsen-Scott \\
\hline
\end{tabular}

emergencies in Antarctica are inevitable, and AMPS will continue to provide assistance.

The AMPS archive. The AMPS archive is a repository of the model forecast output since 2001, containing both MM5 and WRF native-format data. The archive also holds, for ease of use, subsets of the output (namely, selected model fields and levels) in GRIB format. The data storage facility at NCAR, the High-Performance Storage System (HPSS), houses the archive, which currently has well over $100 \mathrm{~TB}$ of data. AMPS archive information is available online (see www.mmm.ucar.edu/rt/wrf/amps/information /archive_info.html). As a more accessible alternative, a subset containing basic model output variables is hosted by OSU's Polar Meteorology Group (see http:// polarmet.osu.edu/PolarMet/ampsdb.html). Potential users of the archive should note that it is not designed as a uniform or reanalysis-type dataset. Because the AMPS model configurations have changed over the years, the archived output does not reflect a fixed benchmark system.

The archive has served a range of research and applications. It has been used for model verification
(Bromwich et al. 2005), climatologies (Monaghan et al. 2005), and regional meteorology (Schlosser et al. 2008; Seefeldt and Cassano 2008; Schlosser et al. 2010). The following specific archive-based investigations have been targeted: mass-energy balance in Antarctica; synoptic conditions in the western Ross Sea, the Dry Valleys, and Adélie Land (Powers 2007; Bromwich et al. 2011); the climate of West Antarctica and of the Dry Valleys (Nicolas and Bromwich 2011; Speirs et al. 2010); assessment of remote sensing (Palm et al. 2011); and the Ross Ice Shelf airstream (Steinhoff et al. 2009). Table 3 presents a sampling.

One specific application was the derivation of a climatology for the Ross Island region. Using the forecast output at 3.3-km resolution, Monaghan et al. (2005) produced detailed seasonal distributions of temperature and winds in the area, presented the first-ever detailed precipitation maps of the region with identification of the primary source of the moisture, and linked cloud fraction to open-water amounts in the Ross Sea. Figure 8 displays results from this application in the form of a winter mean 2-m temperature distribution. There is a regional 
TABLE 3. Selected applications of AMPS archive. Study area and institution involved shown.

\begin{tabular}{|c|c|}
\hline Study & Institution/activity \\
\hline Antarctic precipitation accumulation & $\begin{array}{l}\text { NASA; Assistance in study to determine Antarctic precipi- } \\
\text { tation accumulation from passive microwave observations }\end{array}$ \\
\hline Icebergs-inverse barometer effect & $\begin{array}{l}\text { University of Chicago; Conditions on large icebergs north } \\
\text { of Ross Island }\end{array}$ \\
\hline Climatology/meteorology of WAIS & $\begin{array}{l}\text { Conditions at various sites to determine local meteorology; } \\
\text { Data used in final selection of WAIS drilling site }\end{array}$ \\
\hline Exploration of extension of season at South Pole & Study of March conditions at Pole \\
\hline Southern Patagonia climate change & $\begin{array}{l}\text { Analysis of conditions at Cordillera Darwin ice core site for } \\
\text { support of field drilling activities }\end{array}$ \\
\hline Temperature structures over East Antarctica & University of Illinois at Chicago; University of Portland \\
\hline Ross Ice Shelf energy balance & $\begin{array}{l}\text { University of Canterbury; New Zealand energy and mass } \\
\text { balance study }\end{array}$ \\
\hline Structure and dynamics of Ross Ice Shelf & University of Colorado \\
\hline Surface mass balance in Lambert/Amery Basin & Shanghai Normal University \\
\hline Evaluation of moisture fields over Antarctica & Old Dominion University \\
\hline $\begin{array}{l}\text { Refining of gravity recovery measurements over Antarctica } \\
\text { from GRACE satellite }\end{array}$ & $\begin{array}{l}\text { The Ohio State University; Gravity Recovery and Climate } \\
\text { Experiment; Model fields used to process pressure and } \\
\text { precipitation signals }\end{array}$ \\
\hline Glacier mass-energy balance study & Portland State University \\
\hline Analysis of MM5 and ECMWF models over East Antarctica & Italian Antarctic Program \\
\hline PBL over Larsen Ice Shelf & British Antarctic Survey \\
\hline Snowdrift retrieval method & NASA Goddard Space Flight Center \\
\hline Land surface processes in Dry Valleys & Jet Propulsion Laboratory \\
\hline Foehn winds over Antarctic Peninsula & University of East Anglia \\
\hline McMurdo area fog studies & University of Wisconsin-Madison \\
\hline Verification & The Ohio State University; NCAR \\
\hline
\end{tabular}

gradient with much colder temperatures to the southeast over the Ross Ice Shelf (lower right) and warmer temperatures north of the Ross Ice Shelf edge and over the Ross Sea.

Miscellaneous applications. Various applications outside of USAP operations or field campaigns have exploited AMPS. Site climatologies (i.e., point specific, as opposed to regional), for instance, have been based on archived output as a proxy for in situ observations at field locations. The modelbased climatologies can give an idea of expected weather at a site, which is critical for planning. One example is the consideration of potential alternate McMurdo-area airfield locations. Pegasus Runway is one of the main McMurdo airfields and is situated about $16 \mathrm{~km}$ south of McMurdo Station (Fig. 2c) on permanent ice. Another airstrip, Ice Runway, is closer to McMurdo, but must shut down in the midseason when the underlying sea ice deteriorates.
To explore the possibility of a single airfield serving the whole season, AMPS has yielded estimates of the weather at alternative sites to Pegasus, which are closer to McMurdo (Fig. 9). Figure 9 shows model-based seasonal (October-March) precipitation in the area for the years $2008-11$ based on the 1.67-km Ross Island domain (Fig. 2c) forecasts. The precipitation increases significantly in going from Pegasus to alternative site 1 (Alt. 1) and alternative site 2 [Alt. 2; consistent with the lower-resolution climatology of Monaghan et al. (2005) described in "The AMPS archive" section]. This kind of information has proved to be valuable and cost effective for planning.

Workshops and education. Because it has served a diverse range of interests, AMPS has been an important part of annual workshops drawing Antarctic groups together. The AMPS effort began hosting its own workshops in 2002, and from 2003 to 2005, 


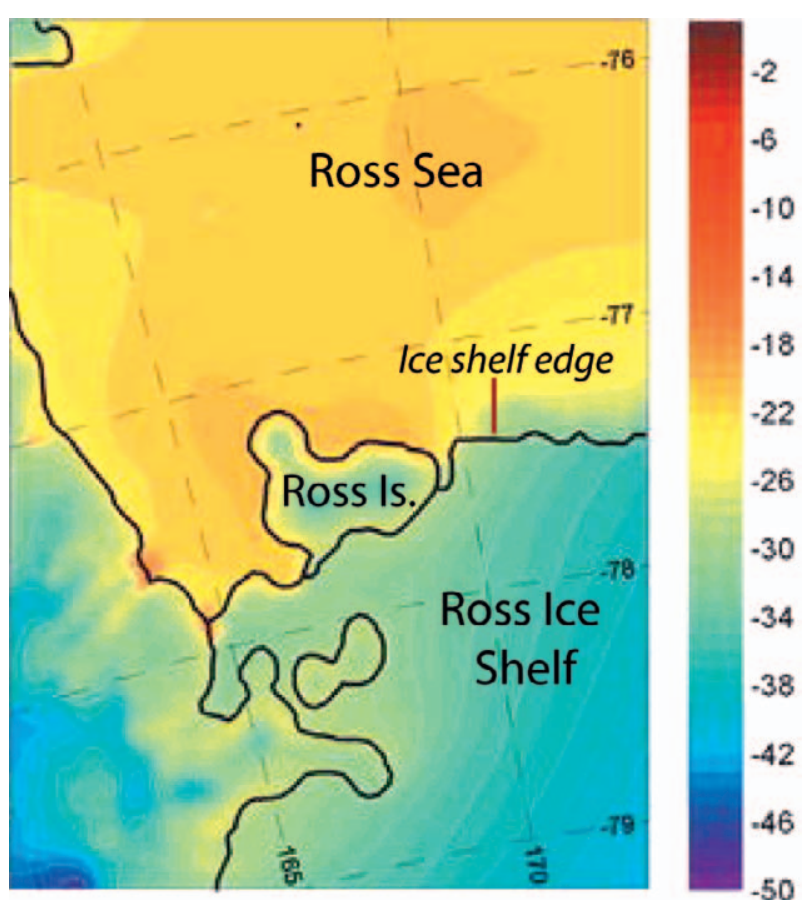

FIG. 8. Ross Island region mean 2-m temperature $\left({ }^{\circ} \mathrm{C}\right)$ for Jun-Aug (JJA) 2002 based on AMPS archived output (from Monaghan et al. 2005).

these occurred in tandem with the annual meetings of the Antarctic Meteorological Research Center and the (Antarctic) Automatic Weather Station (AWS) Program. In 2006 the three meetings were combined to create the Antarctic Meteorological Observation, Modeling, and Forecasting (AMOMF) Workshop. Since then, the AMOMF workshops have been a unifying forum for the international community with both logistical and research interests in Antarctic weather.

AMPS has also supported education. Graduate students and forecasters have used AMPS and its archive for study of Antarctic meteorology and modeling. Both OSU and the University of Colorado have had graduate students whose thesis work used AMPS. In addition, NCAR has hosted SPAWAR forecasters, graduate students, and scientists for training and research. As part of the outreach effort of the 2007-09 International Polar Year, a web-based educational module on the challenges of weather forecasting in Antarctica ("Antarctica: Challenging Forecasts for a Challenging Environment"; see www.meted.ucar.edu/training_module .php? id=27l) was designed by the Cooperative Program for Operational Meteorology Education and Training (COMET; see http://ucar.comet.edu) program using AMPS products and interviews with its scientists.

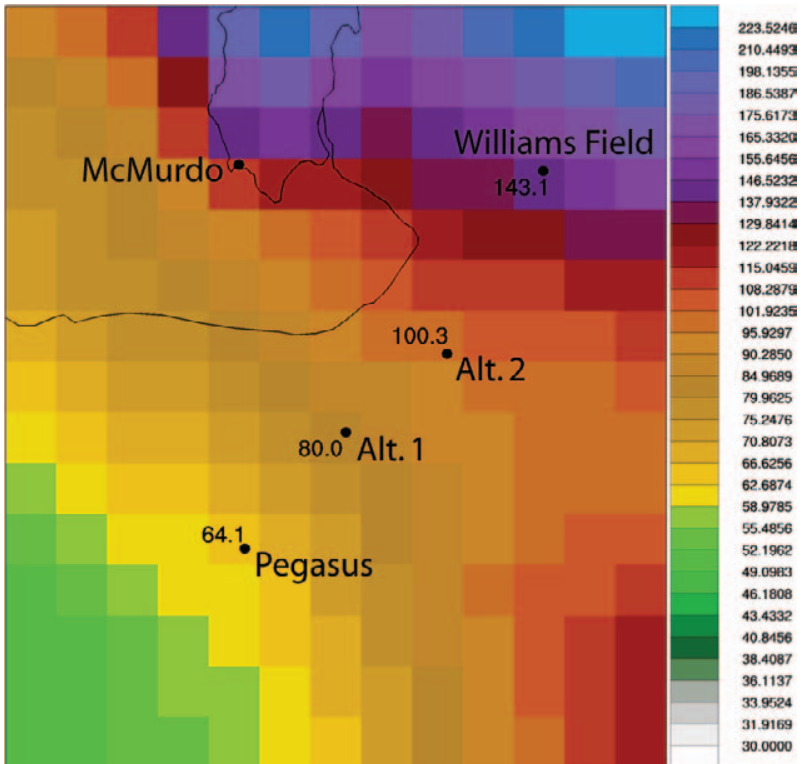

Fig. 9. Accumulated precipitation $(\mathrm{mm})$ based on AMPS forecasts in Pegasus area for field seasons (OctMar) in the 2008-II period. Locations of Pegasus Field, Alt. I, Alt. 2, and Williams Field are shown.

SUMMARY AND FUTURE DIRECTIONS.

AMPS has now been serving Antarctic scientific and logistical needs for over a decade. This mesoscale NWP system currently centers on a real-time implementation of the WRF model optimized for Antarctica. While AMPS was developed with the priority mission of supporting NSF forecasting, over the years it has expanded to a spectrum of applications. These include research, field campaigns, and emergencies.

The original goals of the AMPS effort, all now accomplished, were as follows: to provide tailored, real-time model guidance for the USAP Antarctic forecasters; to improve model physics for Antarctic applications; to perform model verification; and to stimulate collaboration among forecasters, modelers, and researchers. The AMPS webpage freely provides products reflecting user input. The development of model polar modifications (e.g., Bromwich et al. 2009) has improved WRF for the worldwide user community. AMPS verification is performed periodically and has been done both via long-term review and case study (see, e.g., Bromwich et al. 2003, 2005; Powers 2007; Nigro et al. 2011b). The creation of the annual Antarctic Meteorological Observation, Modeling, and Forecasting Workshop has yielded a forum for fostering collaborations in Antarctic science and operations. AMPS has also been a context for operational meteorologists to work with the scientific 
community, fostering the collaboration of research and operations. Last, AMPS's support of Antarctic emergencies (e.g., medevac assistance) and special needs (e.g., research vessels and site planning) has been an unanticipated contribution. AMPS's ability to respond to immediate and changing requests has contributed to the effort exceeding the original goals.

For the future AMPS will target improvements in WRF and in system capabilities. There will be an increase in computing power as the new NCARWyoming Supercomputing Center comes online in 2012 (see http://nwsc.ucar.edu). ${ }^{7}$ One goal for AMPS is increased horizontal resolution, with a target of a continent-wide grid spacing of $10 \mathrm{~km}$. This would translate to a Ross Island grid of $1.1 \mathrm{~km}$. This $33 \%$ enhancement would better define Hut Point Peninsula, on which McMurdo is located and averages just under $4.5 \mathrm{~km}$ in width.

The advancement of WRF modifications for the high latitudes will also continue. While collaborators at OSU and NCAR will address this primarily, outside developers' polar contributions to WRF are welcome as part of the traditional growth of the model. The AMPS archive will be maintained, with a view to improving its ease of use.

The AMPS effort envisions continued service to the USAP, to science across Antarctica, and to the diverse disciplines that make up the Antarctic community. The AMPS partners look for the second decade to be as productive as the first and encourage readers to contact them if AMPS could benefit their Antarctic science plans.

ACKNOWLEDGMENTS. The authors wish to recognize their colleague and friend the late Dr. Neil D. Adams of the Australian Bureau of Meteorology for his advancements to Antarctic NWP and contributions to the international Antarctic effort. The authors thank the National Science Foundation Office of Polar Programs and the NSF UCAR and Lower Atmospheric Facilities Oversight Section for their support of AMPS over the years. They appreciate the Space and Naval Warfare Systems Center and Scientific Research Corporation for their input and collaborations. They also acknowledge NCAR's Computational and Informational Systems Laboratory for its support of the computer hardware systems vital to running AMPS. This work has been funded primarily by the NSF Office of Polar Programs.

\footnotetext{
${ }^{7}$ This will be the supercomputing facility for NCAR and the community and will support high-performance computing in the atmospheric and related sciences.
}

\section{REFERENCES}

Adams, N. D., 2004: A numerical modeling study of the weather in East Antarctica and the surrounding Southern Ocean. Wea. Forecasting, 19, 653-672.

— 2010: Verification of numerical weather prediction systems employed by the Australian Bureau of Meteorology over East Antarctica during the 2009-10 summer season. Extended Abstracts, Fifth Antarctic Meteorological Observation, Modeling, and Forecasting Workshop, Columbus, OH, Byrd Polar Research Center Polar Meteorology Group. [Available online at http://polarmet.osu.edu/workshops /amomfw_2010.]

Barker, D. M., W. Huang, Y.-R. Guo, A. J. Bourgeois, and Q.-N. Xiao, 2004: A three-dimensional (3DVAR) data assimilation system for use with MM5: Implementation and initial results. Mon. Wea. Rev., 132, 897-914.

Bromwich, D. H., 1991: Mesoscale cyclogenesis over the southwestern Ross Sea linked to strong katabatic winds. Mon. Wea. Rev., 119, 1736-1753.

—, and J. J. Cassano, 2001: Meeting summary: Antarctic Weather Forecasting Workshop. Bull. Amer. Meteor. Soc., 82, 1409-1413.

— - _ - T. Klein, G. Heinemann, K. M. Hines, K. Steffen, and J. E. Box, 2001: Mesoscale modeling of katabatic winds over Greenland with the Polar MM5. Mon. Wea. Rev., 129, 2290-2309.

_- A. J. Monaghan, J. G. Powers, J. J. Cassano, H.-L. Wei, Y.-H. Kuo, and A. Pellegrini, 2003: Antarctic Mesoscale Prediction System (AMPS): A case study from the 2000-01 field season. Mon. Wea. Rev., 131, 412-434

- _ - K. W. Manning, and J. G. Powers, 2005: Realtime forecasting for the Antarctica: An evaluation of the Antarctic Mesoscale Prediction System (AMPS). Mon. Wea. Rev., 133, 579-603.

—, K. M. Hines, and L.-S. Bai, 2009: Development and testing of Polar Weather Research and Forecasting Model: 2. Arctic Ocean. J. Geophys. Res., 114, D08122, doi:10.1029/2008JD010300.

— D. F. Steinhoff, I. Simmonds, K. Keay, and R. L. Fogt, 2011: Climatological aspects of cyclogenesis near Adélie Land Antarctica. Tellus, 63A, 921-938.

Cassano, J. J., J. E. Box, D. H. Bromwich, L. Li, and K. Steffen, 2001: Evaluation of Polar MM5 simulations of Greenland's atmospheric circulation. J. Geophys. Res., 106 (D24), 33 867-33890.

- , P. Uotila, A. H. Lynch, and E. N. Cassano, 2007: Predicted changes in synoptic forcing of net precipitation in large Arctic river basins during the 21st century. J. Geophys. Res., 112, G04S49, doi:10.1029/2006JG000332. 
—, J. A. Maslanik, C. J. Zappa, A. L. Gordon, R. I. Cullather, and S. L. Knuth, 2010: Observations of Antarctic polynya with unmanned aerial systems. Eos, Trans. Amer. Geophys. Union, 91, 245-246.

—, M. E. Higgins, and M. W. Seefeldt, 2011: Performance of the Weather Research and Forecasting (WRF) model for month-long pan-Arctic simulations. Mon. Wea. Rev., 139, 3469-3488.

Engels, R., and G. Heinemann, 1996: Three-dimensional structures of summertime Antarctica meso-scale cyclones: Part II: Numerical simulations with a limited area model. Global Atmos. Ocean Syst., 4, 181-208.

Gallée, H., 1995: Simulation of mesocyclonic activity in the Ross Sea, Antarctica. Mon. Wea. Rev., 123, 2051-2069.

Grell, G. A., J. Dudhia, and D. R. Stauffer, 1995: A description of the fifth-generation Penn State/NCAR Mesoscale Model (MM5). NCAR Tech. Note TN-398 + STR, 122 pp. [Available online at www.mmm.ucar .edu/mm5/documents/mm5-desc-doc.html.]

Guo, Z., D. H. Bromwich, and J. J. Cassano, 2003: Evaluation of Polar MM5 simulations of Antarctic atmospheric circulation. Mon. Wea. Rev., 131, 384-411.

Hewitson, B. C., and R. G. Crane, 2002: Self-organizing maps: Applications to synoptic climatology. Climate Res., 22, 13-26.

Hines, K. M., and D. H. Bromwich, 2008: Development and testing of Polar WRF. Part I: Greenland ice sheet meteorology. Mon. Wea. Rev., 136, 1971-1989.

- - — L.-S. Bai, M. Barlage, and A. G. Slater, 2011: Development and testing of Polar WRF. Part III: Arctic land. J. Climate, 24, 26-48.

Lazzara, M. A., G. Langbauer, K. W. Manning, R. Redinger, M. W. Seefeldt, R. Vehorn, and T. Yoksas, 2006: Antarctic Internet Data Distribution (Antarctic-IDD) System. Preprints, 22nd Int. Conf. on Interactive Information Processing Systems for Meteorology, Oceanography, and Hydrology, Atlanta, GA, Amer. Meteor. Soc., 6.10. [Available online at https://ams.confex.com/ams/pdfpapers/100352.pdf.]

Monaghan, A. J., D. H. Bromwich, H.-L. Wei, A. M. Cayette, J. G. Powers, Y.-H. Kuo, and M. A. Lazzara, 2003: Performance of weather forecast models in the rescue of Dr. Ronald Shemenski from the South Pole in April 2001. Wea. Forecasting, 18, 142-160.

- — - J. G. Powers, and K. W. Manning, 2005: The climate of the McMurdo, Antarctica region, as represented by one year of forecasts from the Antarctic Mesoscale Prediction System. J. Climate, 18, 1174-1189.

Nicolas, J. P., and D. H. Bromwich, 2011: Climate of West Antarctica and influence of marine air intrusions. J. Climate, 24, 49-67.
Nielsen, J. A., 2001: Icebound: A Doctor's Incredible Battle for Survival at the South Pole. Miramax, 362 pp.

Nigro, M. A., J. J. Cassano, and S. L. Knuth, 2011a: Evaluation of Antarctic Mesoscale Prediction System (AMPS) cyclone forecasts using infrared satellite imagery. Antarct. Sci., 24, 183-192.

,$- \ldots$, and M. W. Seefeldt, 2011b: A weather patternbased approach to evaluate the Antarctic Mesoscale Prediction System (AMPS) forecasts: Comparison to automatic weather station observations. Wea. Forecasting, 26, 184-198.

NOAA Environmental Modeling Center, 2003: The GFS Atmospheric Model. NCEP Office Note 442, 14 pp. [Available online at www.emc.ncep.noaa.gov /officenotes/newernotes/on442.pdf.]

O’Connor, W. P., D. H. Bromwich, and J. F. Carrasco, 1994: Cyclonically forced barrier winds along the Transantarctic Mountains near Ross Island. Mon. Wea. Rev., 122, 137-150.

Palm, S. P., Y. Yang, J. D. Spinhirne, and A. Marshak, 2011: Satellite remote sensing of blowing snow properties over Antarctica. J. Geophys. Res., 116, D16123, doi:10.1029/2011JD015828.

Parish, T. R., and K. T. Waight, 1987: The forcing of Antarctic katabatic winds. Mon. Wea. Rev., 115, 2214-2226.

—, and D. H. Bromwich, 1991: Continental-scale simulation of the Antarctic katabatic wind regime. J. Climate, 4, 135-146.

Powers, J. G., 2007: Numerical prediction of an Antarctic severe wind event with the Weather Research and Forecasting (WRF) Model. Mon. Wea. Rev., 135, 3134-3157.

—, 2009: Performance of the WRF V3.1 polar modifications in an Antarctic severe wind event. Preprints, 10th WRF Users' Workshop, Boulder, CO, NCAR. [Available online at www.mmm.ucar.edu/wrf/users /workshops/WS2009/abstracts/P3B-26.pdf.]

—, A. J. Monaghan, A. M. Cayette, D. H. Bromwich, Y.-H. Kuo, and K. W. Manning, 2003: Mesoscale modeling over Antarctica: The Antarctic Mesoscale Prediction System (AMPS). Bull. Amer. Meteor. Soc., 84, 1533-1546.

Schlosser, E., M. G. Duda, J. G. Powers, and K. W. Manning, 2008: Precipitation regime of Dronning Maud Land, Antarctica, derived from Antarctic Mesoscale Prediction System (AMPS) archive data. J. Geophys. Res., 113, D24108, doi:10.1029/2008JD009968.

_-, K. W. Manning, J. G. Powers, M. G. Duda, G. Birnbaum, and K. Fujita, 2010: Characteristics of high-precipitation events in Dronning Maud Land, Antarctica. J. Geophys. Res., 115, D14107, doi:10.1029/2009JD013410. 
Seefeldt, M. W., and J. J. Cassano, 2008: An analysis of low-level jets in the greater Ross Ice Shelf region based on numerical simulations. Mon. Wea. Rev., 136, 4188-4205.

, G. J. Tripoli, and C. R. Stearns, 2003: A highresolution numerical simulation of the wind flow in the Ross Island region, Antarctica. Mon. Wea. Rev., 131, 435-458.

Skamarock, W. C., and Coauthors, 2008: A description of the Advanced Research WRF version 3. NCAR
Tech. Note NCAR/TN-475+STR, 125 pp. [Available online at www.mmm.ucar.edu/wrf/users/docs /arw_v3.pdf.]

Speirs, J. C., D. F. Steinhoff, H. A. McGrowan, D. H. Bromwich, and A. J. Monaghan, 2010: Foehn winds in the McMurdo Dry Valleys, Antarctica: The origin of extreme warming events. J. Climate, 23, 3577-3598. Steinhoff, D. F., S. Chaudhuri, and D. H. Bromwich, 2009: A case study of a Ross Ice Shelf airstream event: A new perspective. Mon. Wea. Rev., 137, 4030-4046. 